\begin{tabular}{|c|l|}
\hline Title & $\begin{array}{l}\text { Biosynthetic study of FR-900848: unusual observation on polyketide biosynthesis that did not accept acetate as origin } \\
\text { of acetyl-CoA }\end{array}$ \\
\hline Author(s) & Watanabe, Hiroaki; Tokiwano, Tetsuo; Oikawa, Hideaki \\
\hline Citation & $\begin{array}{l}\text { Tetrahedron Letters, 47(9), 1399-1402 } \\
\text { https://doi.org/10.1016/.tetlet.2005.12.091 }\end{array}$ \\
\hline Issue Date & 2006-02-27 \\
\hline Doc URL & http://hdl.handle.net/2115/5813 \\
\hline Type & article (author version) \\
\hline File Information & TL47-9.pdf \\
\hline
\end{tabular}

Instructions for use 


\title{
Biosynthetic Study of FR-900848: Unusual Observation on Polyketide Biosynthesis that Did Not Accept Acetate as Origin of Acetyl-CoA
}

\author{
Hiroaki Watanabe, Tetsuo Tokiwano and Hideaki Oikawa* \\ Division of Chemistry, Graduate School of Science, Hokkaido University, Sapporo 060-0810, Japan
}

\begin{abstract}
The biosynthetic pathway of a potent antifungal agent, FR-900848, has been examined by administration of several ${ }^{13}$ C-labeled precursors to Streptoverticillium fervens HP-891. Although none of the ${ }^{13} \mathrm{C}$-labeled acetate was incorporated into FR-900848, the labeling pattern of FR-900848 derived from $\mathrm{D}-\left[\mathrm{U}-{ }^{13} \mathrm{C}_{6}\right]$ glucose revealed that the fatty acid backbone of FR-900848 has been biosynthesized via a polyketide pathway. These unusual results strongly show that the major pathway to provide acetyl-CoA in this microorganism is glycolysis. Feeding experiments with $\mathrm{D}-\left[\mathrm{U}-{ }^{13} \mathrm{C}_{6}\right]$ glucose, $\left[1,3-{ }^{13} \mathrm{C}_{2}\right]$ glycerol and $\mathrm{L}-\left[\mathrm{Me}-{ }^{13} \mathrm{C}\right]$ methionine provided information on the biosynthetic origin of structurally unusual parts (polycyclopropane and aminonucleoside) in this antibiotic.
\end{abstract}

Keywords: FR-900848; antifungal agent; biosynthesis; polyketide; polycyclopropane; aminonucleoside.

* Corresponding author. Tel.: +81-11-706-2622; fax.: +81-11-706-3448; e-mail: hoik@sci.hokudai.ac.jp

FR-900848 (1) is an antifungal agent isolated from Streptoverticillium fervens HP-891 by Yoshida et al. in $1990 .^{1}$ FR-900848 was found to have potent activity against phytopathogenic fungi suppressing their growth. The structure of $\mathbf{1}$ including the absolute stereochemistry was established by degradation and synthetic studies to be as shown in Figure $1 .^{2}$ FR-900848 consists of a 2,4,14-octadecatrienoic acid having four contiguous and one isolated cyclopropanes, and a 
5"-amino-5"-deoxy-5',6'-dihydrouridine. Closely related polycyclopropane compound U-106305 (2), a cholesteryl ester transfer protein (CETP) inhibitor, was isolated from Streptomyces sp. UC 11136 by Kuo et al., ${ }^{3}$ and was found to have the same stereochemistry for cyclopropane rings. In order to elucidate the mechanism constructing the polycyclopropane, we have started on a biosynthetic study of $\mathbf{1}$, and herein describe the biosynthetic origins of structurally unique polycyclopropane and aminonucleoside units, and an unusual observation on the polyketide biosynthesis.

Before conducting the biosynthetic study, we faced a problem in the purification of $\mathbf{1}$. Conversion of $\mathbf{1}$ to diacetate $\mathbf{3}$ at crude mycelial extracts significantly improved its recovery in a series of chromatography. Although the ${ }^{13} \mathrm{C}-\mathrm{NMR}$ data of $\mathbf{1}$ was reported, the assignment of signals has not been done. Thus, the signals of 3 in both ${ }^{1} \mathrm{H}$ - and ${ }^{13} \mathrm{C}$-NMR spectra were unambiguously assigned based on extensive 2D-NMR analysis including COSY, HSQC, and HMBC.

To elucidate the biosynthetic origin of the FR-900848 carbon skeleton, incorporation studies of ${ }^{13} \mathrm{C}$-labeled precursors were conducted. ${ }^{4}$ Feeding experiment with L-[Me- $\left.{ }^{13} \mathrm{C}\right] \mathrm{methionine}$ to Streptoverticillium fervens HP-891 gave diacetate 3. In the ${ }^{13} \mathrm{C}-\mathrm{NMR}$ spectra of labeled $\mathbf{3}$, strongly enhanced signals were observed at cyclopropane methylenes C19, C20, C21, C22 and C23 (Table 1). In the case of administration with $\left[1-{ }^{13} \mathrm{C}\right]$ acetate, however, no incorporation was observed. Use of $\left[1,2-{ }^{13} \mathrm{C}_{2}\right]$ acetate which is expected to be more effective in detection of ${ }^{13} \mathrm{C}$-enriched signals also failed to detect any incorporation. These results were unexpected since Kuo et al. reported that structurally related long-chain cyclopropanoid 2 is biosynthesized via a polyketide pathway. ${ }^{3 a}$ 
Glucose is a universal precursor of major biosynthetic pathways of secondary metabolites such as polyketide, mevalonate, shikimate, alkaloid pathways. Thus, D-[U- $\left.{ }^{13} \mathrm{C}_{6}\right]$ glucose was frequently used to define the biosynthetic pathway with analysis of ${ }^{13} \mathrm{C}-{ }^{13} \mathrm{C}$ coupling patterns in natural products labeled. ${ }^{4}$ When $\mathrm{D}-\left[\mathrm{U}-{ }^{13} \mathrm{C}_{6}\right.$ ]glucose was administered to the cultures, the ${ }^{13} \mathrm{C}-\mathrm{NMR}$ spectra of 3 obtained showed pairs of doublet signals on the long-chain fatty acid at C1 through C18 (Table 1). This result can be explained by $\mathrm{D}-\left[\mathrm{U}_{-}{ }^{13} \mathrm{C}_{6}\right]$ glucose converted to acetyl-CoA via pyruvate and the resultant $\left[1,2-{ }^{13} \mathrm{C}_{2}\right]$ acetyl-CoA was introduced to the fatty acid backbone (Scheme 1). Feeding $\left[1,3-{ }^{13} \mathrm{C}_{2}\right]$ glycerol enhanced signals preferentially at C2, 4, 6, 8, 10, 12, 14, 16, and C18 (Table 1). This also supports that $\left[1,3-{ }^{13} \mathrm{C}_{2}\right]$ glycerol was metabolized into $\left[2-{ }^{13} \mathrm{C}\right]$ acetyl-CoA (Scheme 1 ) which was incorporated into the fatty acid moiety. It is generally accepted that most organisms utilize acetate as a carbon source of polyketides. In this case, acetate is converted by acetyl-CoA synthetase via adenylation and the subsequent attack of CoA-thiolate. The reason for inability to incorporate acetate could be attributed to inactivation of acetyl-CoA synthetase. These unusual results in S. fervens strongly show that the major pathway to provide acetyl-CoA in this microorganism is glycolysis. In the feeding experiment with $\left[{ }^{13} \mathrm{C}\right]$ acetates, lack of the ${ }^{13} \mathrm{C}$-label in the dihydrouracil moiety of $\mathbf{3}$ agrees with this conclusion.

Analysis of the ${ }^{13} \mathrm{C}-\mathrm{NMR}$ spectrum of 3 from the feeding experiment with $\mathrm{D}-\left[\mathrm{U}_{-}{ }^{13} \mathrm{C}_{6}\right]$ glucose provided information on the biosynthetic pathway of the aminonucleoside moiety (Scheme 1). Although overlapped signals at C2" and C3" did not give useful data on the coupling patterns, observation of doublets at C1", C4", C5" and a triplet at C4" (ribose unit) clearly showed the presence of ${ }^{13} \mathrm{C}$-labels at adjacent positions as shown in Scheme 1 . The observed ${ }^{13} \mathrm{C}$-labeling 
pattern (Figure 2, r1-r4) suggested that the ribose unit of $\mathbf{1}$ is derived via the pentose phosphate pathway from the $\mathrm{D}-\left[\mathrm{U}_{-}-{ }^{13} \mathrm{C}_{6}\right]$ glucose or from partially ${ }^{13} \mathrm{C}$-labeled glucose constructed by the ${ }^{13} \mathrm{C}_{3}$-units (glyceraldehyde-3-phosphate and dihydroxyacetone-phosphate). ${ }^{5 \mathrm{~d}}$ On the other hand, the labeling pattern (doublets at C4', C5', C6', and a double doublet at C5') of the dihydrouracil moiety (C4'-C5'-C6') contained a mixture of ${ }^{13} \mathrm{C}_{3}$ - and two alternative ${ }^{13} \mathrm{C}_{2}$-units. This nucleoside part should originate from aspartate which can be derived from acetyl-CoA via oxalacetate. Efficient reconstruction of oxaloacetate from two molecules of ${ }^{13} \mathrm{C}_{2}$-acetyl-CoA may explain the formation of ${ }^{13} \mathrm{C}_{3}$ units.

Enhanced signals at $\mathrm{C}^{\prime} / \mathrm{C} 6$ ' and $\mathrm{C} 3 " / \mathrm{C} 5 "$ in the spectrum of $\mathbf{1}$ from $\left[1,3-{ }^{13} \mathrm{C}_{2}\right]$ glycerol supported intact incorporation of the C3-units in the ribose and dihydrouracil units, respectively, though the presence of ${ }^{13} \mathrm{C}$-labels at multiple positions indicates significant scrambling occurred. Similar scrambling of ${ }^{13} \mathrm{C}$-labels via the pentose phosphate pathway ${ }^{5}$ and the TCA cycle has been reported. ${ }^{6}$

In summary, the biosynthetic origin of structurally unique polycyclopropanoid FR-900848 has been elucidated by a series of feeding experiments. During this study, we found an unusual observation that the polyketide backbone of FR-900848 was constructed by acetyl-CoA derived from glucose but not from acetate. To clarify the detailed mechanism of the polycyclopropanation, we are currently identifying the actual biosynthetic intermediate and the biosynthetic gene cluster. 


\section{Acknowledgements}

We are grateful to Dr. Hideyuki Muramatsu of Astellas Pharmaceutical Co. Ltd. for supplying Streptoverticillium fervens HP-891 and the fermentation conditions, and to Prof. H. G. Floss of University of Washington for comments on our observation, and to High Resolution NMR Laboratory, Faculty of Science, Hokkaido University, for NMR measurement.

\section{References}

1. Yoshida, M.; Ezaki, M.; Hashimoto, M.; Yamashita, M.; Shigematsu, N.; Okuhara, M.; Kohsaka, M.; Horikoshi, K. J. Antibiot. 1990, 43, 748-754.

2. Barrett, A. G. M.; Doubleday, W. W.; Kasdorf, K.; Tustin, G. J. J. Org. Chem. 1996, 61, 3280-3288.

3. (a) Kuo, M. S.; Zielinski, R. J.; Cialdella, J. I.; Marschke, C. K.; Dupuis, M. J.; Li, G. P.; Kloosterman, D. A.; Spilman, C. H.; Marshall, V. P. J. Am. Chem. Soc. 1995, 117, 10629-10634; (b) Barrett, A. G. M.; Hamprecht, D.; White, A. J. P.; Williams, D. J. J. Am. Chem. Soc. 1997, 119, 8608-8615.

4. Feeding experiments with isotopically labeled compounds: culture medium and growth conditions for Streptoverticillium fervens HP-891 were as described by Yoshida et al. ${ }^{1}$ Culture medium $(100 \mathrm{ml})$ in a $500 \mathrm{ml}$ Erlenmeyer flask was inoculated with a well-grown slant culture of the strain. The flask was shaken on a rotary shaker (180 rpm) at $30{ }^{\circ} \mathrm{C}$ for 3 days. The resultant cultures (10 ml per one flask) were poured into two to four Erlenmeyer flasks containing $100 \mathrm{ml}$ of a fermentation medium. On the fourth day after inoculation, the sterilized aqueous solution of a labeled compound (50 mg per one flask) was added to the cultures. After 
further incubation for 5 day, The mycelia were extracted with acetone. The crude extracts were treated with acetic anhydride, pyridine, and dimethylaminopyridine. Purification of the products by silica gel column chromatography and reverse-phase HPLC afforded FR-900848 diacetate 3 (1.6 to $5.4 \mathrm{mg})$.

5. (a) Gould, S. J.; Cane, D. E. J. Am. Chem. Soc. 1982, 104, 343-346; (b) Brahme, N. M.; Gonzalez, J. E.; Mizsak, S.; Rolls, J. R.; Hessler, E. J.; Hurley, L. H. J. Am. Chem. Soc. 1984, 106, 7878-7883; (c) Cane, D. E.; Wu, Z.; Van Epp, J. E. J. Am. Chem. Soc. 1992, 114, 8479-8483; (d) Gupta, R. N.; Hemscheidt, T.; Sayer, B. G.; Spenser, I. D. J. Am. Chem. Soc. 2001, 123, 11353-11359.

6. (a) Ubukata, M.; Uzawa, J.; Isono, K. J. Am. Chem. Soc. 1984, 106, 2213-2214; (b) Nomura, T.; Hano, Y. Nat. Prod. Rep. 1994, 11, 205-218. 
Table 1. ${ }^{13} \mathrm{C}$ NMR data of diacetate 3 derived from ${ }^{13} \mathrm{C}$-labeled precursors. ${ }^{a}$

\begin{tabular}{|c|c|c|c|c|c|}
\hline & \multirow[b]{2}{*}{$\delta(\mathrm{ppm})$} & \multicolumn{2}{|c|}{$\mathrm{D}-\left[\mathrm{U}_{-}{ }^{13} \mathrm{C}_{6}\right.$-]glucose } & \multirow{2}{*}{$\begin{array}{l}{\left[1,3-{ }^{13} \mathrm{C}_{2}\right] \text { glycerol }} \\
\text { enrichment }^{b}\end{array}$} & \multirow{2}{*}{$\begin{array}{c}{\left[\mathrm{Me}^{\left.-{ }^{13} \mathrm{C}\right] \mathrm{L}-\mathrm{methionine}}\right.} \\
\text { enrichment }^{b}\end{array}$} \\
\hline & & multiplicity & $J_{\mathrm{C}-\mathrm{C}}(\mathrm{Hz})$ & & \\
\hline 1 & 167.0 & $\mathrm{~d}$ & 66.4 & 1.27 & \\
\hline 2 & 119.6 & $\mathrm{~d}$ & 65.5 & 2.21 & \\
\hline 3 & 147.4 & d & 55.6 & 1.16 & \\
\hline 4 & 125.3 & d & 56.4 & 2.53 & \\
\hline 5 & 142.0 & $\mathrm{~d}$ & 56.4 & 1.03 & \\
\hline 6 & 21.6 & $\mathrm{~d}$ & 56.4 & 2.02 & \\
\hline 7 & 24.1 & d & 54.8 & 1.35 & \\
\hline 8 & 18.0 & d & 54.7 & 1.64 & \\
\hline 9 & 18.8 & & $-^{c}$ & 0.91 & \\
\hline 10 & 18.4 & & $-{ }^{c}$ & 1.63 & \\
\hline 11 & 18.2 & d & 54.7 & 0.99 & \\
\hline 12 & 21.8 & d & 56.4 & 1.49 & \\
\hline 13 & 20.0 & $\mathrm{~d}$ & 56.4 & 1.14 & \\
\hline 14 & 130.5 & d & 56.4 & 1.60 & \\
\hline 15 & 131.1 & d & 56.4 & 1.20 & \\
\hline 16 & 22.4 & $\mathrm{~d}$ & 55.6 & 1.59 & \\
\hline 17 & 14.80 & d & 43.9 & 1.29 & \\
\hline 18 & 18.5 & d & 43.1 & 1.57 & \\
\hline $19-\mathrm{CH}_{2}$ & 13.4 & & & 1.31 & 11.0 \\
\hline $20-\mathrm{CH}_{2}$ & 7.7 & & & 1.42 & 21.5 \\
\hline $21-\mathrm{CH}_{2}$ & 7.6 & & & 1.56 & 21.5 \\
\hline $22-\mathrm{CH}_{2}$ & 11.5 & & & 1.03 & 13.8 \\
\hline $23-\mathrm{CH}_{2}$ & 14.82 & & & 1.21 & 19.3 \\
\hline $2^{\prime}$ & 152.6 & & & 1.61 & \\
\hline $4^{\prime}$ & 169.2 & d & 47.9 & 1.64 & \\
\hline \multirow[t]{3}{*}{$5^{\prime}$} & 31.0 & d & 33.0 & 1.38 & \\
\hline & & d & 48.7 & & \\
\hline & & dd & $33.2,48.1$ & & \\
\hline $6^{\prime}$ & 39.1 & d & 33.8 & 2.42 & \\
\hline 1" & 88.9 & d & 45.4 & 1.31 & \\
\hline $2 "$ & 70.6 & & $-{ }^{c}$ & 0.99 & \\
\hline $3 "$ & 70.9 & & $-{ }^{c}$ & 1.71 & \\
\hline \multirow[t]{2}{*}{$4 "$} & 79.4 & d & 39.8 & 1.20 & \\
\hline & & $\mathrm{t}$ & 40.7 & & \\
\hline 5" & 40.8 & d & 41.3 & 2.87 & \\
\hline 2"-- $\mathrm{CH}_{3} \underline{\underline{C}} \mathrm{O}_{2}$ & 169.9 & & & & \\
\hline 2"- $\underline{\underline{C}} \mathrm{H}_{3} \mathrm{CO}_{2}$ & 20.52 & & & & \\
\hline 3"-- $\mathrm{CH}_{3} \underline{\underline{C}} \mathrm{O}_{2}$ & 170.0 & & & & \\
\hline 3"- $\underline{\mathbf{C}} \mathrm{H}_{3} \mathrm{CO}_{2}$ & 20.53 & & & & \\
\hline
\end{tabular}

${ }^{a}$ The ${ }^{13} \mathrm{C}$ NMR spectra were measured in $\mathrm{CDCl}_{3} .{ }^{b}$ The values of enrichments were determined by comparison of the relative peak intensities of the corresponding carbons in labeled and non-labeled spectra. ${ }^{c}$ The values could not be obtained since the corresponding signals were overlapped. 